\title{
The cost of anal cancer in England: retrospective hospital data analysis and Markov model
}

\author{
Sam T Keeping ${ }^{1 \dagger}$, Michael J Tempest ${ }^{2 *}$, Stephanie J Stephens ${ }^{2 \dagger}$, Stuart M Carroll ${ }^{1 \dagger}$, Karen P Nugent ${ }^{3 \dagger}$ \\ and Sarah T O'Dwyer ${ }^{4 \dagger}$
}

\begin{abstract}
Background: Anal cancer requires a multidisciplinary approach to treatment with often complex interventions. Little is known regarding the associated costs and resource use.

Methods: Patient records were extracted from a national hospital database to estimate the number of patients treated for anal cancer in England. Identified resource use was linked to published UK cost estimates to quantify the reimbursement of treatment through the Payment by Results system. A mathematical model was developed simultaneously to validate findings and to calculate the average 10-year cost of treating a squamous cell anal carcinoma case from diagnosis. The model utilised data from the Association of Coloproctology of Great Britain and Ireland's anal cancer position statement.

Results: On average, 1,564 patients were admitted to hospital and 389 attended an outpatient facility per year. The average annual cost per inpatient and outpatient ranged from $£ 4,562-£ 5,230$ and $£ 1,146-£ 1,335$, respectively. Based on the model estimates, the inflated cost per case was between $£ 16,470-£ 16,652$. Results were most sensitive to the mode of admission for primary treatment and the costs of staging/diagnosis (inflated range: $£ 14,309-£ 23,264$ ).

Conclusions: Despite limitations in the available data, these results indicate that the cost of treating anal cancer is significant. Further observational work is required in order to verify these findings.
\end{abstract}

Keywords: Anal cancer, England, Reimbursement, Resource use

\section{Background}

Anal cancer is a rare disease, accounting for around 4\% of large bowel malignancies [1]. More than $80 \%$ of the estimated 1,100 cases of anal cancer that are diagnosed each year in the United Kingdom [2] are squamous cell carcinomas, the putative aetiological agent for which is human papillomavirus (HPV) [3], with adenocarcinomas the next most commonly observed tumour ( 10\%) [1]. Far less common are anal melanomas, lymphomas and sarcomas [1]. Some evidence suggests that the incidence of anal cancer is increasing, with age standardised rates per 100,000 rising from 0.7 to 1.1 and 0.6 to 1.3 between 1986 and 2003 in English males and females, respectively $[4,5]$. Recent epidemiology studies have postulated that the increase in anal cancer incidence is attributable to

\footnotetext{
* Correspondence: mtempest@pharmerit.com

${ }^{\dagger}$ Equal contributors

${ }^{2}$ Pharmerit Ltd, Enterprise House, Innovation Way, York YO10 5NQ, UK Full list of author information is available at the end of the article
}

changes in sexual behaviour (i.e. a higher number of unprotected receptive anal sex partners), a likely surrogate for infection with multiple high-risk HPV strains [6]. Interestingly the incidence of anal cancer has dramatically increased among HIV-infected men, despite antiviral therapy (e.g. during and proceeding the HAART era) [7]. One potential explanation for this is that whilst antiviral therapy may reduce competing mortality risks, it has no impact on the impact on the natural history of HPV nor the likelihood or HPV co-infection and, moreover, increasing life expectancy allows sufficient time for the accumulation of genetic mutations implicated in the development of anal cancer. Such data highlights the need for preventative strategies for anal cancer [7].

Anal cancer is a slow progressing disease and local disease failures after primary treatment normally go on to develop metastatic disease. Therefore, the main goal of curative treatment is achieving adequate local control [8]. Optimal primary treatment involves chemoradiotherapy, 
although a small number of patients are unable to tolerate the full treatment regime and are at risk of residual disease as a result [9]. Radical salvage surgery remains the primary option for those who experience locoregional relapse [10].

Changes in the treatment approach away from primary surgical intervention have required a shift to a multidisciplinary model of patient management [1]. In England and Wales, specialist anal cancer multi-disciplinary teams (MDTs) have been established within and across cancer networks, with all referrals of suspected cases being discussed during regular meetings [11]. This is also in keeping with a general strategy aimed at improving outcomes for rarer cancers, with similar arrangements in place for penile cancer, which is another HPV-related genital cancer [12].

In contrast to the well-developed literature on treatment options for anal cancer, very little has been published on the costs and resource use associated with treating the condition. In the last ten years, only two economic evaluations of treatment for anal cancer have been carried out in the UK setting $[4,13]$. Both of these extrapolated costs from research on other cancers: one from a study of colorectal cancer [14] and the other from two studies of cervical cancer costs $[15,16]$.

In order to inform future economic analysis, this study reports an estimate of both the mean annual costs of treating anal cancer in England, and also the average cost of treating a single case of the most common type of anal cancer, squamous cell carcinoma, in line with the Association of Coloproctology of Great Britain and Ireland's anal cancer position statement [1,8,11,17-21].

\section{Methods}

The study was split into two phases. Firstly, a retrospective (non-comparative) case series was performed using data extracted from the Hospital Episode Statistics (HES) database. HES includes records of all care funded by the English National Health Service (NHS), allowing the economic burden associated with pre-cancerous and invasive anal cancer lesions in England to be estimated. Due to the short span of extracted data years, the exclusion of primary care, the inability to distinguish between initial and recurrent cases, and the lack of information pertaining to the cancer stage; a separate mathematical model was developed to simulate the treatment pathway for an anal cancer case of squamous origin in order to estimate the average cost of treating a single patient.

\section{HES data collection}

For inpatients, finished consultant episodes (FCE) were extracted based on the presence of any of the following International Classification of Diseases, $10^{\text {th }}$ (ICD-10) codes in either the primary, secondary of tertiary diagnosis field: C210 - malignant neoplasm of anus, unspecified; C211 - malignant neoplasm of anal canal, C212 - malignant neoplasm of cloacogenic zone, C218 malignant neoplasm overlapping lesion of rectum, anus and anal cancer, and D013 - carcinoma in situ of anus and anal canal. Data on outpatient attendances were confined to records with a primary or secondary diagnosis only, reflecting the more disease specific nature of post-treatment care.

Data were collected for care delivered in the period from 2006 to 2011. As our HES data request was submitted prior to the publication of full year results for $2010 / 2011$, the final year was only representative of nine months of activity in both patient settings.

Approval for use of the HES data was provided by the information asset owner from the Health and Social Care Information Centre (HSCIC). The individual HES records extracted contained no sensitive data and were pseudonymised preventing the true identification of patients; analyses pertaining to HES records adhered to published regulations [22]. Ethical approval was not required as secondary analysis of HES data can be used to identify public health issues and for general medical research under existing protocol; the Health Research Authority decision tool corroborated this fact stating no ethical approval was required for this research [23].

\section{Data aggregation and costing}

The number of patients undergoing treatment for anal cancer in each year of the study period was determined by tracing the unique patient identifiers (HESID) assigned to each FCE. Mean annual patient numbers were then calculated. HES data aggregation and the generation of descriptive statistics was carried out using SAS Enterprise Guide 4.3.

NHS funded healthcare providers in England are reimbursed under the Payment by Results (PbR) scheme [24]. The currencies for payment under $\mathrm{PbR}$ are healthcare resource groups (HRG). Each year, payment tariffs for each HRG are determined using retrospective analysis of costing data submitted from previous years. In order to derive relevant HRGs for care delivered to anal cancer patients, inpatient FCEs were aggregated into spells of care (from hospital admission to discharge) using software publicly available from the NHS [25]. Similarly, for non-admitted patient care (outpatient), Treatment Function Codes (TFC) and associated HRGs for consultations or minor procedures were generated. For all core HRGs and TFCs, costs were calculated using the National Tariff 2010/11 [26]. Costing analyses were performed in Excel 2007.

Costs were applied on a per spell basis, accounting for adjustments such as those for non-elective admissions, and then aggregated by year. For the final year in the 
study period, for which data was only representative of nine months of activity, costs and patient numbers were scaled up by a factor of 1.33 , assuming no seasonality in treatment patterns or propensity to consult.

The annual estimates were then used to calculate mean annual costs for the duration of the study period, with mean annual cost per patient calculated by dividing this by the mean annual number of patients. All analyses were split by gender, with results for those diagnosed with carcinoma in situ of the anus and anal canal also presented separately to those with invasive disease due to the anticipated differences in treatment intensity for this group.

Under the latest version of HRGs (version 4), some significant elements of cost and activity (e.g. chemotherapy, radiotherapy and rehabilitation) have been 'unbundled' from the core HRGs. The frequency of unbundled HRGs was also captured, with costs associated with the procurement and administration of chemotherapy and radiotherapy also disaggregated. Unbundled HRGs are excluded from the National Tariff due to wide variation in regional practices and costs, with prices negotiated locally. To derive costs for these unbundled HRGs, the associated codes were cross-referenced and matched by description to codes in the Reference Cost Tariffs [27] for the year of interest. Earlier tariff years were utilised in the presence of unmatchable codes and inflated accordingly using the consumer price index (CPI) [28].

\section{Estimating costs over the duration of treatment}

To estimate the average cost of treatment for a case of anal cancer a mathematical model was constructed to capture the costs of referral through to follow-up, taking into account the impact of primary treatment on the duration and intensity of the latter. Due to a lack of data on outcomes for patients with primary adenocarcinoma, the model was restricted to anal cancer patients with squamous cell carcinoma. Data on primary treatment, disease progression and follow-up for this group were obtained from the Association of Coloproctology of Great Britain and Ireland's anal cancer position statement, supplemented by expert opinion where necessary. First, decision trees were constructed to estimate the costs of diagnosis, staging, including pre-treatment interventions such as colostomy surgery, and primary treatment. A Markov model was then developed to simulate disease progression and follow-up based on the mode of primary treatment (chemo radiotherapy vs. radiotherapy).

The structure of the Markov portion of the model can be seen in Figure 1. A one month cycle length was used and the model was run over a timeframe of ten years (the extent of high risk follow-up). The initial conditions assumed that all patients who receive either radiotherapy or chemo radiotherapy as primary curative treatment are left disease free. Patients experiencing relapse were assumed to stay in the relapse state for one month only, representing the period during which salvage interventions occur. Salvage was assumed to be in the form of abdominoperineal resection (APR).

Monthly probabilities for relapse, death from the disease free-state and death post relapse (assumed to be the same for those undergoing salvage or follow-up) were estimated by calibrating the model to empirical data. Values for these unknown parameters were jointly selected from within plausible ranges, with simulations run in batches of 1,000. The best fitting set of values, determined by comparing the model output to longitudinal

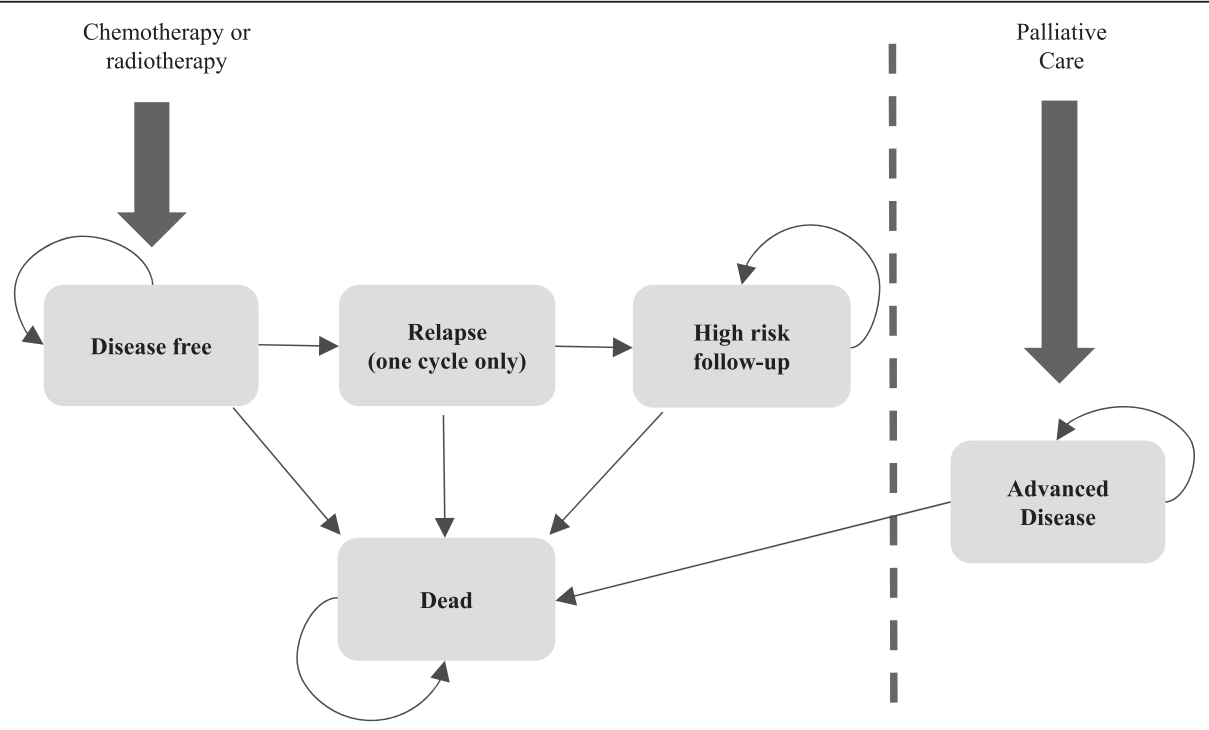

Figure 1 Markov model structure. 
data on overall mortality and loco-regional relapse [29] using least squares from each batch of simulations were then used to determine the ranges from which values were selected in the next round. We ceased to run simulations at the point when no improvements were observed in the overall goodness-of-fit at three significant figures.

All costs applied to treatments and interventions were taken from the 2010/11 National Tariff, with the 2010/11 Reference Costs used for off tariff payments. Two scenarios for pricing were examined: 1) with no future inflation in prices and 2) where future inflation was assumed to remain constant at 2011/12 levels for the duration of follow-up [28]. The aim of our approach was to estimate realised costs as opposed to modelling an investment decision, therefore discounting was deemed to be inappropriate. A one-way sensitivity analysis was also performed for the following key inputs: type of admission for primary treatment, cost of staging and primary treatment, monthly costs of palliative care, intensity of follow-up, proportion of patients undergoing salvage surgery, proportion of patients presenting with advanced disease, cost of follow-up interventions and the proportion of patients receiving chemo radiotherapy.

Full details of all the model inputs can be found in the Additional file 1.

\section{Results}

\section{Number of patients}

From 2006-2011, the mean number of patients admitted to hospital each year in England for invasive anal cancers was 1,564 (Table 1). Approximately $30 \%$ more females than males were admitted each year on average (mean: male $=642$; female $=922$ ). Over the same period on average 389 patients attended outpatient facilities each year for anal cancer (mean: male $=139$; female $=250$ ). The mean start age for anal cancer treatment was 64 and 65 for males and females, respectively (data not shown).

\section{Hospital spells and outpatient attendances}

On average, there were 4,674 hospital spells and 3,564 outpatient attendances each year. Male patients were associated with a mean of 3 hospital spells and 10 outpatient attendances. Female patients had the same number of hospital spells on average but one less outpatient attendance. Across genders, the mean length of an inpatient hospital stay was 4 days.

Eighty-five per cent of hospital spells were elective admissions and 33\% were day case admissions across both genders. Excess bed days were observed in 10\% of male elective hospital spells and $11 \%$ of female elective hospital spells. For non-elective spells, excess bed days were observed in 3\% for both males and females.

The most frequent HRGs were diagnosis driven anal disorders of varying severity, representing $47 \%$ of male hospital spells and $51 \%$ of female hospital spells. Anal procedures were the second most observed HRG across both genders accounting for $8 \%$ of hospital spells. Large intestine disorders and procedures were observed in $12 \%$ and $8 \%$ of male and female hospital spells, respectively.

Chemotherapy sessions (procurement and delivery) were observed in $12 \%$ and $11 \%$ of male and female hospital spells. Radiotherapy sessions (procurement and delivery) were observed in $7 \%$ of male hospital spells and $9 \%$ of female spells. Across genders, palliative care was associated with $1 \%$ and rehabilitation $<1 \%$ of hospital spells.

Minor outpatient procedures were observed in $2 \%$ of all attendances. Follow-up consultations were the most frequent HRG observed in $90 \%$ of male and $89 \%$ of female attendances. The most frequent TFC observed was clinical oncology in $87 \%$ and $89 \%$ of male and female attendances, respectively. Chemotherapy sessions were observed in $1 \%$ of male and $<1 \%$ female attendances, radiotherapy sessions were observed in $29 \%$ and $33 \%$ of male and female attendances, respectively. Palliative care and rehabilitation was observed in $<1 \%$ of all attendances.

\section{Economic burden}

All costs presented considered a direct healthcare perspective and are presented in GBP (2011 prices). The mean annual cost per patient (setting dependent) is provided in Table 1 . The mean annual cost per inpatient

Table 1 Mean annual number of patients, hospital spells, outpatient attendances and cost per patient (2006-2011)

\begin{tabular}{|c|c|c|c|c|c|c|}
\hline & \multicolumn{3}{|c|}{ Inpatient } & \multicolumn{3}{|c|}{ Outpatient } \\
\hline & $\begin{array}{l}\text { Number of spells } \\
\text { (SD) }\end{array}$ & $\begin{array}{l}\text { Number of patients } \\
\text { (SD) }\end{array}$ & $\begin{array}{l}\text { Cost per patient } \\
\text { (SD) }\end{array}$ & $\begin{array}{l}\text { Number of attendances } \\
\text { (SD) }\end{array}$ & $\begin{array}{l}\text { Number of patients } \\
\text { (SD) }\end{array}$ & $\begin{array}{l}\text { Cost per patient } \\
\text { (SD) }\end{array}$ \\
\hline \multicolumn{7}{|c|}{ Anal cancer } \\
\hline Male & $1743(69)$ & $642(87)$ & $£ 4,562(£ 431)$ & $1377(381)$ & $139(21)$ & $£ 1335$ (£596) \\
\hline Female & $2931(290)$ & $922(81)$ & $£ 5230(£ 332)$ & 2187 (727) & $250(65)$ & $£ 1146(£ 374)$ \\
\hline \multicolumn{7}{|c|}{ Anal carcinoma in situ } \\
\hline Male & $70(5)$ & $58(14)$ & $£ 881$ (£336) & $8(16)$ & $1(1)$ & $£ 1240(£ 1276)$ \\
\hline Female & $133(32)$ & $110(32)$ & $£ 1145(£ 126)$ & $7(2)$ & $2(1)$ & $£ 326(£ 70)$ \\
\hline
\end{tabular}

SD, Standard Deviation. 
was estimated at $£ 4,562$ and $£ 5,230$ for males and females, respectively. Costs per outpatient were calculated at $£ 1,335$ for males and $£ 1,146$ for females.

Table 2 provides the total annual cost for anal cancer defined by gender and per type of care.

For male inpatients, $£ 2,658,450$ was attributable to bundled costs which include all care received in a hospital setting excluding unbundled HRGs such as chemotherapy, radiotherapy, rehabilitation, palliative care, specific diagnostic imaging and high cost drugs. Annual unbundled costs (excluding chemotherapy and radiotherapy) were equal to $£ 61,026$. Respectively, chemotherapy and radiotherapy cost $£ 88,783$ and $£ 122,103$ per year.

Of the total burden associated with male outpatients, $£ 120,265$ was attributable to bundled costs and £5,096 to unbundled elements of care (excluding chemotherapy and radiotherapy). Respectively, chemotherapy and radiotherapy cost $£ 8,332$ and $£ 51,214$ per year.

Female anal cancer patients were associated with payments for bundled HRGs totalling $£ 4,351,222$ for inpatients and $£ 191,725$ for outpatients; $£ 88,273$ for inpatient and $£ 6,426$ outpatient unbundled costs (excluding chemotherapy and radiotherapy); $£ 132,493$ and $£ 2,420$ for inpatient and outpatient chemotherapy, and $£ 251,870$ and $£ 86,129$ for inpatient and outpatient radiotherapy, respectively.

Across genders and settings, bundled costs accounted for $89 \%$ of the total annual burden. Unbundled costs accounted for $2 \%$, chemotherapy and radiotherapy accounted for $3 \%$ and $6 \%$, respectively. Analysing this trend, it is clear that the proportion of the cost attributable to chemotherapy and radiotherapy has been increasing, although this is thought to be predominantly due to improvements in correct clinical coding as opposed to changes in the treatment paradigm (Figure 2).

\section{Total costs for duration of treatment}

Figure 3 shows the model predictions for cumulative allcause mortality and relapse, compared to data from the
UKCCR Anal Cancer Trial (ACT 1), for the best fitting set of parameters which could be achieved through the calibration process.

The average cost of treating a case of invasive anal cancer from referral through to either completion of follow-up or death was estimated to be $£ 16,473$ (between $£ 14,335$ and $£ 23,089$ based on sensitivity analysis) when future inflation was taken into account and $£ 16,281$ (between $£ 14,143$ and $£ 22,884$ ) when it was not. For those undergoing treatment with curative intent, the majority of costs were accrued during staging, primary treatment and the twelve months of follow-up post referral, with annual costs in the following years ranging from $£ 338$ to $£ 815$ (uninflated $£ 308$ - $£ 807$ ) and $£ 363$ to $£ 1,452$ (uninflated $£ 338-£ 1,437$ ), for those undergoing chemoradiotherapy and radiotherapy alone, respectively.

Figure 4 shows the results of the one-way sensitivity analysis used to construct the ranges around the base case estimates for the inflated scenario (Table 3). The results were most sensitive to changes in the mode of admission for primary treatment, reflecting the higher costs associated with primary treatment that requires longer patient stays. Changes in the cost of staging and primary treatment also had a marked impact on the results, highlighting once again that initial interventions were the main drivers of total costs. Another implication of this was that the proportion undergoing salvage had a limited impact on the results, despite these procedures being extremely resource intensive.

\section{Discussion}

With incidence of anal cancer on the increase, better information on treatment costs will assist in defining future service specifications for commissioning and delivery of treatment. Although not an incremental analysis in itself, this study provides the first attempt to estimate the cost of treating anal cancer in England, and potentially allows for better assessment of the cost-

Table 2 Mean total annual costs per category of cost from the payers' perspective

\begin{tabular}{|c|c|c|c|c|c|c|c|c|c|}
\hline & \multicolumn{4}{|c|}{ Inpatient } & \multicolumn{4}{|c|}{ Outpatient } & \multirow[t]{2}{*}{ Total } \\
\hline & Bundled (SD) & $\begin{array}{l}\text { Unbundled* } \\
\text { (SD) }\end{array}$ & $\begin{array}{l}\text { Chemo-therapy } \\
\text { (SD) }\end{array}$ & $\begin{array}{l}\text { Radio-therapy } \\
\text { (SD) }\end{array}$ & $\begin{array}{c}\text { Bundled } \\
\text { (SD) }\end{array}$ & $\begin{array}{l}\text { Unbundled* } \\
\text { (SD) }\end{array}$ & $\begin{array}{l}\text { Chemo-therapy } \\
\text { (SD) }\end{array}$ & $\begin{array}{l}\text { Radio-therapy } \\
\text { (SD) }\end{array}$ & \\
\hline \multicolumn{10}{|c|}{ Anal cancer } \\
\hline Male & $\begin{array}{l}£ 2,658,450 \\
(£ 152,591)\end{array}$ & $\begin{array}{c}£ 61,026 \\
(£ 46,809)\end{array}$ & $\begin{array}{c}£ 88,783 \\
(£ 36,680)\end{array}$ & $\begin{array}{l}£ 122,103 \\
(£ 34,585)\end{array}$ & $\begin{array}{l}£ 120,265 \\
(£ 32,687)\end{array}$ & $\begin{array}{c}£ 5,096 \\
(£ 7,034)\end{array}$ & $\begin{array}{c}£ 8,332 \\
(£ 12,664)\end{array}$ & $\begin{array}{c}£ 51,214 \\
(£ 57,976)\end{array}$ & $£ 3,115,267$ \\
\hline Female & $\begin{array}{l}£ 4,351,222 \\
(£ 338,353)\end{array}$ & $\begin{array}{c}£ 88,273 \\
(£ 49,798)\end{array}$ & $\begin{array}{l}£ 132,493 \\
(£ 52,957)\end{array}$ & $\begin{array}{l}£ 251,870 \\
(£ 50,504)\end{array}$ & $\begin{array}{l}£ 191,725 \\
(£ 62,773)\end{array}$ & $\begin{array}{c}£ 6,426 \\
(£ 8,774)\end{array}$ & $\begin{array}{c}£ 2,420 \\
(£ 3,082)\end{array}$ & $\begin{array}{c}£ 86,129 \\
(£ 86,632)\end{array}$ & $£ 5,110,560$ \\
\hline \multicolumn{10}{|c|}{ Anal carcinoma in situ } \\
\hline Male & $\begin{array}{l}£ 49,272 \\
(£ 8,042)\end{array}$ & $\begin{array}{c}£ 563 \\
(£ 1,196)\end{array}$ & $\begin{array}{l}£ 487 \\
(£ 614)\end{array}$ & $\begin{array}{c}£ 1,144 \\
(£ 1,527)\end{array}$ & $\begin{array}{c}£ 744 \\
(£ 1,276)\end{array}$ & $£ 0$ & $£ 0$ & $£ 0$ & $£ 52,211$ \\
\hline Female & $\begin{array}{l}£ 125,091 \\
(£ 32,803)\end{array}$ & $\begin{array}{c}£ 133 \\
(£ 209)\end{array}$ & $\begin{array}{l}£ 296 \\
(£ 446)\end{array}$ & $\begin{array}{l}£ 407 \\
(£ 772)\end{array}$ & $\begin{array}{c}£ 553 \\
(£ 186)\end{array}$ & $\begin{array}{c}£ 141 \\
(£ 216)\end{array}$ & $£ 0$ & $£ 0$ & $£ 126,622$ \\
\hline
\end{tabular}

*Excludes chemotherapy and radiotherapy; SD, Standard Deviation. 


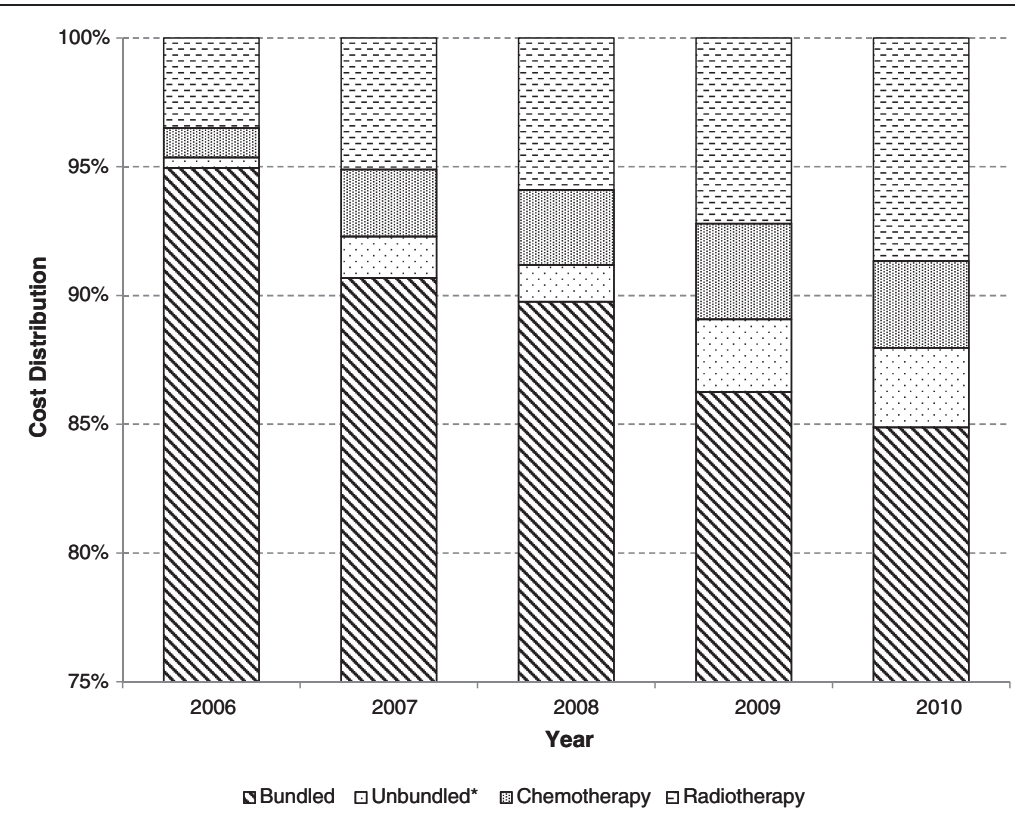

Figure 2 Total annual cost distribution per category of care for invasive anal cancer. * Excludes chemotherapy \& radiotherapy.

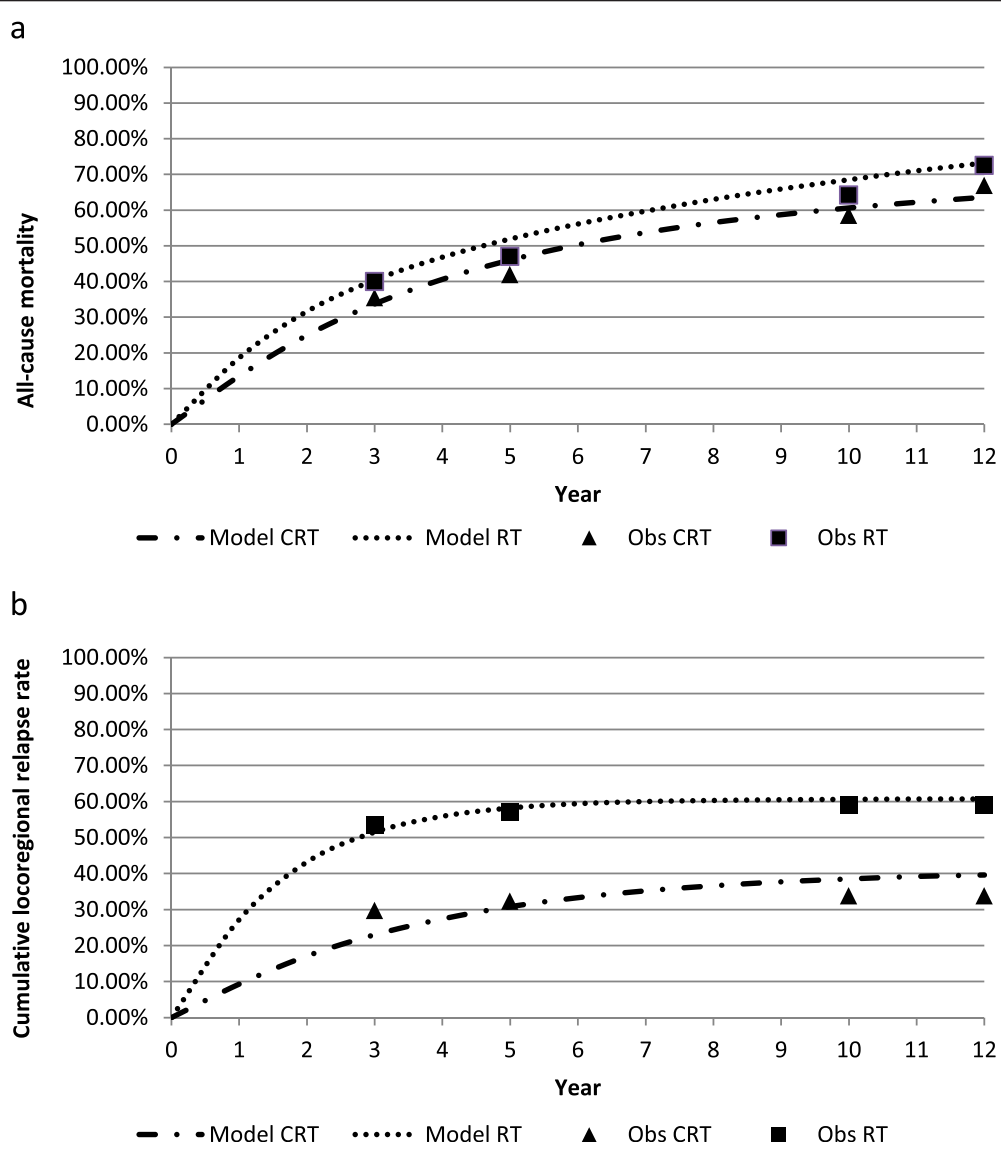

Figure 3 Predicted a) all-cause mortality and b) cumulative relapse compared to data from the UKCCCR anal cancer trial (ACT 1). 


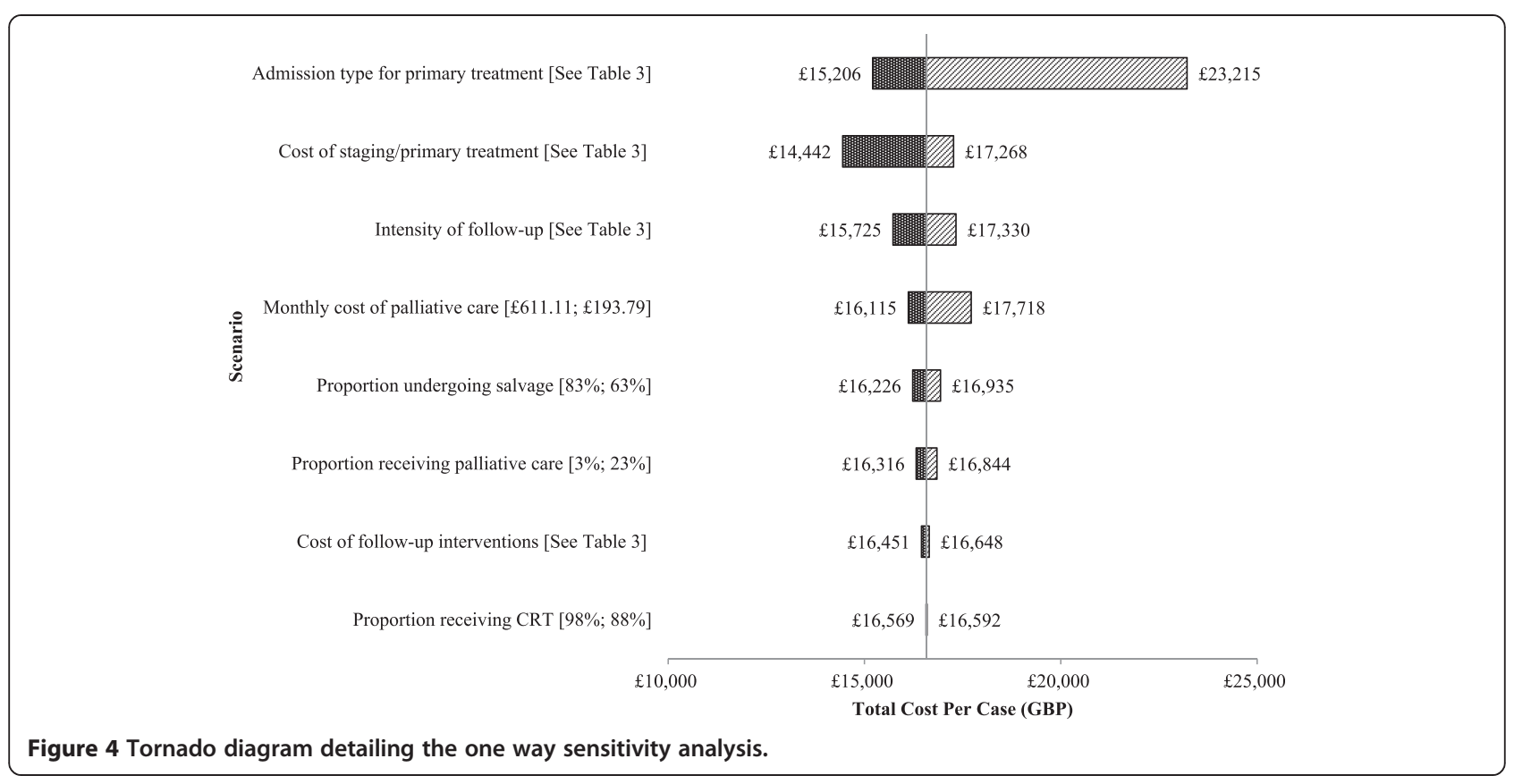

effectiveness of new treatments for anal cancer through the determination of the costs of current best available treatment. As with any new data analysis, the research suffers from some limitations. These mainly stem from the structure of the HES database and the lack of available data on disease progression, and associated treatment patterns, for anal cancer.

Firstly it should be acknowledged that despite the non-comparative case-series study design, the inherent bias noted with this approach was limited in the present study. Patient records were extracted from all English hospitals based on the aforementioned ICD-10 codes only with no additional inclusion or exclusion criteria applied. Furthermore, cases were retrieved retrospectively with all information collected routinely in relevant medical records. Nonetheless, restricting the presence of an ICD-10 code up to the tertiary and secondary diagnoses fields for inpatient and outpatients, respectively may have introduced some selection bias, for example by excluding adverse treatment events such as neutropenic sepsis and radiation proctitis. However, relaxing the this restriction may have introduced costs completely unrelated to anal cancer.

In the HES portion of the analysis, it is evident that the link between the MDT and clinical coders is inefficient; most notably in the earlier data years extracted. Fields such as patient age, sex, admission and discharge methods, hospital provider codes and codes pertaining to diagnosis and operational procedures are mandatory in the grouping process from FCEs to spells of care and the derivation of the dominant and correct HRGs; the prevalence of missing fields and thus erroneous coding was higher within these data years, leading to potential underestimations within the economic analysis. The coding errors are recognised under $\mathrm{PbR}$ and frameworks are in place to reduce the percentage of errors in order to improve the quality of data that underpins $\mathrm{PbR}$. Between 2007/08 and 2009/10, the audit commission looked at over $£ 200$ million of payments for admitted patient care, and observed an improvement in the accuracy of clinical coding during this period. The coding error rate dropped from $16 \%$ to $11 \%$ in three years, although there remains a wide variation between the best and worst performing providers. Coding errors occur at a clinical level and ultimately affect payments. The Audit Commission estimate that of the $£ 21$ billion spent on the four specialities they audited for three years, $£ 1$ billion (5\%) was incorrectly paid [24].

Furthermore, despite HES records containing exhaustive data fields, other key information pertaining to a patient's diagnosis would have proved valuable within the analyses. For example, ICD-10 codes provide a platform for extracting all records related to anal cancer. However, it does not provide information pertaining to a patient's cancer stage, or if a tumour is primary vs. recurrent. One would naturally assume a higher cost and more intense resource use as the cancer stage progresses. This distinction could not be made and therefore restricted the performed analysis.

The length of time over which resource use could be analysed was also constrained by changes to the coding methodology used in PbR. Data was originally extracted from 2002/03 to 2010/11 and spanned several versions of HRG. When aggregating FCEs into spells of care, it 
Table 3 Upper and Lower values implemented in the one-way sensitivity analysis

\begin{tabular}{|c|c|c|}
\hline Scenario/variable & Upper value & Lower value \\
\hline \multicolumn{3}{|l|}{ Admission type for primary treatment* } \\
\hline Radiotherapy planning & $£ 2,869$ & $£ 729$ \\
\hline PICC line insertion & $£ 2,068$ & $£ 751$ \\
\hline Procure 5-FU & $£ 339$ & $£ 286$ \\
\hline Initial 5-FU cycle delivery & $£ 334$ & $£ 302$ \\
\hline Subsequent 5-FU cycle delivery & $£ 294$ & $£ 206$ \\
\hline Radiotherapy delivery & $£ 261$ & $£ 111$ \\
\hline \multicolumn{3}{|l|}{ Cost of staging/primary treatment ${ }^{\dagger}$} \\
\hline MRI scans & $£ 413$ & $£ 235$ \\
\hline CT scans & $£ 177$ & $£ 116$ \\
\hline Fine needle aspiration & $£ 616$ & $£ 269$ \\
\hline Examination under anaesthetic/biopsy & $£ 1,797$ & $£ 1,117$ \\
\hline Radiotherapy planning & $£ 1,309$ & $£ 674$ \\
\hline Mytomycin C & $£ 48$ & $£ 40$ \\
\hline PICC line insertion & $£ 877$ & $£ 414$ \\
\hline Procure 5-FU & $£ 360$ & $£ 187$ \\
\hline Initial 5-FU cycle delivery & $£ 401$ & $£ 232$ \\
\hline Subsequent 5-FU cycle delivery & $£ 343$ & $£ 210$ \\
\hline Radiotherapy delivery & $£ 134$ & $£ 122$ \\
\hline \multicolumn{3}{|l|}{ Intensity of follow-up } \\
\hline \multicolumn{3}{|l|}{ Low-risk of relapse } \\
\hline Follow-up appointments & 18 & 14 \\
\hline MRI scans & 2 & 0 \\
\hline CT scans & 2 & 0 \\
\hline \multicolumn{3}{|l|}{ High-risk of relapse } \\
\hline Follow-up appointments & 18 & 14 \\
\hline MRI scans & 7 & 5 \\
\hline CT scans & 4 & 2 \\
\hline \multicolumn{3}{|l|}{ Cost of follow-up interventions } \\
\hline MRI scans & $£ 413$ & $£ 235$ \\
\hline CT scans & $£ 177$ & $£ 116$ \\
\hline
\end{tabular}

*Upper and lower values are for inpatient and outpatient costs, respectively.

${ }^{\dagger}$ Based on upper and lower quartile of the reference costs for each item.

was noted that data prior to 2006 omitted chemotherapy and radiotherapy unbundled HRGs. The reason for this was traced to the HRG4 grouping software requirements on OPCS 4.3 codes for procurement and delivery, which were not authored and released to the NHS until April 2006. This resulted in severe data gaps associated with unbundled HRGs from 2002/03 to 2005/06 hence the decision was taken to restrict the analysis to data from 2006 to 2011.

It should also be noted that outpatient data prior to 2006 was deemed as experimental data due to the immaturity of the clinical coding process in this setting. Data after this year are accredited as a national statistic. However, it was increasingly apparent from analysis and observations of the dataset that this is not of equal quality to the inpatient dataset. Clinical experts noted that the observed outpatient numbers were lower than expected: it is expected a patient admitted to hospital would attend the outpatient facility at least once, which was not the case here.

High cost drugs are excluded under PbR and no indication of hospital prescribing data is available within HES. The exclusion of such costs is acknowledged as an analytical limitation. Furthermore, costs associated with unbundled HRGs are not available in the National Tariff 2010/11 due to wide regional variations in resource use and cost; such prices are locally negotiated. We therefore used the national average cost from the National Reference Costs, which provides the foundations for the National Tariff. Definitions for HRGs can alter yearly and inaccurately matching codes and definitions could have potentially led to an underestimation or overestimation.

Nonetheless, the HES analysis does provide the most complete analysis of the overall burden of anal cancers to date and is based on a national database currently used for a range of healthcare analyses for the NHS and Government. It is from this perspective that HES can be seen as a useful starting point for costing analyses. These estimates show that there is a significant burden associated with treatment of the various tumours and provide a benchmark against which any future efficiency improving measures can be judged. Our research also highlights the limitations of the HES database and difficulty of calculating the overall burden of specific cancers in England. Initiatives to improve clinical coding and the functioning of $\mathrm{PbR}$ will be important in aiding future efforts to quantify the cancer burden.

The mathematical modelling was subject to inherent data limitations. Firstly, due to a lack of data on stage at diagnosis and treatment outcomes, we had to assume that for all patients treated with curative intent, regardless of stage, local control was achieved. Although this assumption is unrealistic, its impact is limited as the model allows patients to relapse from the first month post-treatment (assuming a two month gap between treatment and assessment for response) therefore mirroring the treatment which would likely be provided to those with residual disease. Secondly, data on palliative care was also limited requiring assumptions about treatment based on expert opinion, with monthly costs extrapolated from studies of resource use patterns for other tumours. Finally, costs for care delivered during follow-up outside of the standard pattern of appointments, for example those related to stoma nurses, could not be included in the model due to a lack of available information. 
The memory-less property of the Markov model also meant that it was not possible to determine when a particular patient had entered the post-relapse state, and consequently it was not possible to accurately apply the costs of interventions delivered as part of the specified programme of follow-up for high risk patients. Monthly follow-up costs post-relapse were therefore based on an average monthly cost associated with a completed programme of interventions for those with a high-risk of relapse. This inability to account for the distribution of costs for follow-up post salvage surgery, and also the likely need for palliative interventions, has probably led to some overall underestimation in the total costs.

It was also assumed that patients receiving salvage surgery would also undergo some cosmetic or reconstructive surgery. The impact of this assumption was limited by the small amount that salvage surgery contributed to total costs overall. It was also not possible to capture the long term follow-up costs of those undergoing pretreatment colostomy, $90 \%$ of which are not reversed. Overall, the assumptions used suggest that the model is very conservative in estimating overall treatment costs.

Despite these data limitations, the model achieved a good fit to published data on the natural history of anal cancer from follow-up data on participants in ACT 1. The inclusive nature of ACT 1 (those with anal margin and T1 tumours were not excluded despite their favourable prognosis) also helps with the generalisability of the results. Although the model results are not entirely congruent with the per patient costs observed in HES, this is posited to be the result of annual increases in new patients pushing per patient costs upwards due to more resource intensive treatment. The mean annual costs from the model are also deflated somewhat by the ten year timeframe used. The inclusion of tumours other than those of a squamous nature, which are the focus of the mathematical model, may also have contributed to the observed differences.

These data are timely given the increasing number of new interventions aimed at anal cancer, including monoclonal antibodies which have been used to treat other squamous cell carcinomas, such as cetuximab (ERBITUX; ImClone Systems Inc., New York, NY, and BristolMyers Squibb Co, Princeton, NJ), and vaccines against HPV (e.g. Gardasil, a quadrivalent vaccine developed and marketed in the UK by Sanofi Pasteur MSD). Sufficient evidence is available to support the causal relationship between HPV-infection and malignant growths of the anus [30-35]. Low-risk HPV subtypes are more commonly associated with low-grade dysplasia, in contrast to high-risk HPV subtypes (e.g. HPV-16, 18), which are more frequently identified in carcinoma in situ or invasive carcinoma lesions. Population based epidemiological studies suggest between $63 \%$ and $90 \%$ of invasive anal cancers are attributable to HPV [30-35].HPV-16 is the most frequently detected HPV subtype and is prevalent in an estimated $48.6 \%$ to $76.5 \%$ of anal cancer cases $[30,31,33,35]$. Hitherto, economic evaluations of the cost-effectiveness of HPV vaccination in the UK have had to use anal cancer treatment costs extrapolated from other sources. Our findings can be used as an alternative and contribute to a more accurate assessment of the potential value of HPV vaccination.

\section{Conclusions}

Despite being a rare condition, anal cancer patients place a significant burden on NHS resources in England. It is expected that this should decrease as the impact of the current HPV vaccination programme for adolescent girls takes effect. Nonetheless, the reduction may be less than expected given the group most affected by anal cancer, men-who-have-sex-with-men (MSM), do not benefit from the herd protection afforded by the girls programme. Our estimated treatment costs could now be used to better estimate the value and cost-effectiveness of vaccination programmes, particularly those targeted at the male and MSM populations. This could have important implications in terms of the expected net health benefit resulting from preventative healthcare interventions versus existing treatment options and in turn the potential cost offsets to the NHS. The research also provides a benchmark against which further changes to the overall structure of service delivery for anal cancer patients can be judged.

\section{Additional file}

Additional file 1: Model description and parameters.

\section{Abbreviations}

ACT1: Anal cancer trial 1; APR: Abdomino perineal resection; CPI: Consumer price index; FCE: Finished consultant episode; GBP: Great british pounds; HES: Hospital episode statistics; HESID: Hospital episode statistics patient identifier; HPV: Human papillomavirus; HRG: Healthcare resource group; ICD-10: 10th revision of the international statistical classification of diseases and related health problems; MDT: Multi-disciplinary team; MSM: Men-whohave-sex-with-men; NHS: National health service; NICE: National institute of health and clinical excellence; OPCS: Office of population censuses and surveys classification of interventions and procedures; PbR: Payment by results; TFC: Treatment function code; UK: United Kingdom; UKCCR: United Kingdom coordinating committee on cancer research.

\section{Competing interests}

SK and SC are employees of Sanofi Pasteur MSD. MT and ST are employees of Pharmerit Ltd, which has received funding from Sanofi Pasteur MSD. KN and SO'D have received honoraria for attended advisory boards run by Sanofi Pasteur MSD.

\section{Authors' contributions}

SK, SC, SS and MT participated in the study design and acquisition of the data. SK and MT participated in the statistical analysis. All authors participated in the analysis and interpretation of the data and drafting of the manuscript. SC, SS, KN and SO'D conducted a critical revision of the manuscript for important intellectual content. All authors read and approved the final manuscript. 


\section{Author details}

${ }^{1}$ Sanofi Pasteur MSD, Mallards Reach, Bridge Avenue, Maidenhead, Berks SL6 1QP, UK. ${ }^{2}$ Pharmerit Ltd, Enterprise House, Innovation Way, York YO10 5NQ, UK. ${ }^{3}$ Faculty of Medicine, University of Southampton, Southampton General Hospital, Mailpoint 801, South Academic Block, Tremona Road, Southampton SO16 6YD, UK. ${ }^{4}$ The Christie NHS Foundation Trust, Wilmslow Road, Manchester M20 4BX, UK.

Received: 4 February 2014 Accepted: 10 October 2014

Published: 31 October 2014

\section{References}

1. Scholefield JH, Nugent KP: Anal cancer: position statement of the association of coloproctology of Great Britain and Ireland introduction. Colorectal Dis 2011, 13(1):1-2.

2. Risk and causes of anal cancer. http://cancerhelp.cancerresearchuk.org/ type/anal-cancer/about/risks-and-causes-of-anal-cancer.

3. Daling JR, Weiss NS, Hislop TG, Maden C, Coates RJ, Sherman KJ, Ashley RL, Beagrie M, Ryan JA, Corey L: Sexual practices, sexually transmitted diseases, and the incidence of anal cancer. N Engl J Med 1987, 317:973-977.

4. Czoski-Murray C, Karnon J, Jones R, Smith K, Kinghorn G: Cost-effectiveness of screening high-risk HIV-positive men who have sex with men (MSM) and HIV-positive women for anal cancer. Health Technol Assess 2010, 14:1-101. iii-iv, ix-X.

5. Cancer statistics registrations. http://www.ons.gov.uk/

6. Grulich AE, Poynten IM, Machalek DA, Jin F, Templeton DJ, Hillman RJ: The epidemiology of anal cancer. Sex Health 2012, 9:504-508.

7. Crum-Cianflone NF, Hullsiek KH, Marconi VC, Ganesan A, Weintrob A, Barthel RV, Agan BK: Anal cancers among HIV-infected persons: HAART is not slowing rising incidence. AIDS 2010, 24:535-543.

8. Kronfli M, Glynne-Jones R: Chemoradiotherapy in anal cancer. Colorectal Dis 2011, 13(Suppl 1):33-38.

9. Glynne-Jones R, Northover JMA, Cervantes A: Anal cancer: ESMO clinical practice guidelines for diagnosis, treatment and follow-up. Ann Oncol 2010, 21(Suppl 5):v87-v92.

10. Renehan AG, Saunders MP, Schofield PF, O'Dwyer ST: Patterns of local disease failure and outcome after salvage surgery in patients with anal cancer. Br J Surg 2005, 92:605-614.

11. Renehan AG, O'Dwyer ST: Initial management through the anal cancer multidisciplinary team meeting. Colorectal Dis 2011, 13(Suppl 1):21-28,

12. National Institute for Health and Clinical Excellence (NICE): Guidance on Cancer Services. Improving Outcomes in Urological Cancer - The Manual. London, UK: National Institute for Clinical Excellence; 2002:83-85.

13. Jit M, Chapman R, Hughes O, Choi YH: Comparing bivalent and quadrivalent human papillomavirus vaccines: economic evaluation based on transmission model. BMJ 2011, 343:d5775.

14. Tappenden P, Chilcott J, Eggington S, Patnick J, Sakai H, Karnon J: Option appraisal of population-based colorectal cancer screening programmes in England. Gut 2007, 56:677-684.

15. Wolstenholme $J$, Whynes DK: Stage-specific treatment costs for cervical cancer in the United Kingdom. Eur J Cancer 1998, 34:1889-1893.

16. De Rijke JM, van der Putten HWHM, Lutgens LCHW, Voogd AC, Kruitwagen RFPM, van Dijck JAAM, Schouten LJ: Age-specific differences in treatment and survival of patients with cervical cancer in the southeast of The Netherlands, 1986-1996. Eur J Cancer 2002, 38:2041-2047.

17. Scholefield $\mathrm{JH}$, Harris D, Radcliffe A: Guidelines for management of anal intraepithelial neoplasia. Colorectal Dis 2011, 13(Suppl 1):3-10.

18. Salmo E, Haboubi N: Anal cancer: pathology, staging and evidence-based minimum data set. Colorectal Dis 2011, 13(Suppl 1):11-20.

19. Branagan G: Staging and management of inguinal nodes. Colorectal Dis 2011, 13(Suppl 1):29-32.

20. Myint AS: Follow up. Colorectal Dis 2011, 13(Suppl 1):39-43.

21. Renehan AG, O'Dwyer ST: Management of local disease relapse. Colorectal Dis 2011, 13(Suppl 1):44-52.

22. Information Centre: The HES Protocol (June 2009): instructions for handling the data. London: Information Centre; 2009.

23. NHS research ethics committee decision tool. http://www.hradecisiontools.org.uk/ethics/.

24. Payment by results in the NHS: a simple guide. https://www.gov.uk/ government/publications/simple-guide-to-payment-by-results.
25. HRG 4 2010/11 local payment grouper. http://www.hscic.gov.uk/article/ 2332/HRG4-201011-Local-Payment-Grouper-Documentation.

26. Department of Health: 2010-11 national tariff. 2011. http://data.gov.uk/ dataset/payment-by-results-2010-11-national-tariff-information.

27. 2010-11 reference costs. https://www.gov.uk/government/publications/ 2010-11-reference-costs-publication

28. Consumer price indices (August dataset). http://www.ons.gov.uk/ons/rel/ cpi/consumer-price-indices/august-2012/cpi-time-series-data.html.

29. Northover J, Glynne-Jones R, Sebag-Montefiore D, James R, Meadows H, Wan S, Jitlal M, Ledermann J: Chemoradiation for the treatment of epidermoid anal cancer: 13-year follow-up of the first randomised UKCCCR Anal Cancer Trial (ACT I). Br J Cancer 2010, 102:1123-1128.

30. Daling JR, Madeleine MM, Schwartz SM, Shera KA, Carter JJ, MCKnight B, Porter PL, Galloway DA, McDougall JK, Tamimi H: A population-based study of squamous cell vaginal cancer: HPV and cofactors. Gynecol Oncol 2002, 84:263-270.

31. De Vuyst H, Clifford GM, Nascimento MC, Madeleine MM, Franceschi S: Prevalence and type distribution of human papillomavirus in carcinoma and intraepithelial neoplasia of the vulva, vagina and anus: a meta-analysis. Int J Cancer 2009, 124:1626-1636.

32. Hoots BE, Palefsky JM, Pimenta JM, Smith JS: Human papillomavirus type distribution in anal cancer and anal intraepithelial lesions. Int J Cancer 2009, 124:2375-2383.

33. Ogunbiyi OA, Scholefield JH, Robertson G, Smith JH, Sharp F, Rogers K: Anal human papillomavirus infection and squamous neoplasia in patients with invasive vulvar cancer. Obstet Gynecol 1994, 83:212-216.

34. Parkin DM, Bray F: Chapter 2: the burden of HPV-related cancers. Vaccine 2006, 24(Suppl 3):S3/11-25

35. Ogunbiyi OA, Scholefield JH, Smith JH, Polacarz SV, Rogers K, Sharp F: Immunohistochemical analysis of p53 expression in anal squamous neoplasia. J Clin Pathol 1993, 46:507-512.

doi:10.1186/1471-2458-14-1123

Cite this article as: Keeping et al:: The cost of anal cancer in England: retrospective hospital data analysis and Markov model. BMC Public Health 2014 14:1123.

\section{Submit your next manuscript to BioMed Central and take full advantage of:}

- Convenient online submission

- Thorough peer review

- No space constraints or color figure charges

- Immediate publication on acceptance

- Inclusion in PubMed, CAS, Scopus and Google Scholar

- Research which is freely available for redistribution 